\title{
Regulating coexistence of GM and non-GM crops without jeopardizing economic incentives
}

\author{
Matty Demont ${ }^{1,2}$ and Yann Devos ${ }^{3}$ \\ ${ }^{1}$ Africa Rice Center (WARDA), B.P. 96, Saint-Louis, Senegal \\ ${ }^{2}$ Centre of Agricultural and Food Economics, Katholieke Universiteit Leuven, de Croylaan 42, B-3001 Leuven, Belgium \\ ${ }^{3}$ Department of Plant Production, Ghent University, Coupure Links 653, B-9000 Ghent, Belgium
}

The ongoing debate about the coexistence of genetically modified (GM) and non-GM crops in the European Union (EU) mainly focuses on preventive measures needed to keep the adventitious presence of GM material in nonGM products below established tolerance thresholds, as well as on issues covering questions of liability and the duty to redress the incurred economic harm once adventitious mixing in non-GM products has occurred. By contrast, the interplay between the economic incentives and costs of coexistence has attracted little attention. The current overemphasis on the technical aspects and cost of coexistence over its economic incentives might lead EU policy-makers to adopt too stringent and rigid regulations on coexistence. Therefore, we argue for flexible coexistence regulations that explicitly take into account the economic incentives for coexistence. Our arguments provide a timely and important framework for EU policy-makers, who are currently struggling to implement coherent coexistence regulations in all member states.

\section{Introduction}

In 2006, global cultivation of genetically modified (GM) crops exceeded 100 million hectares for the first time. In the European Union (EU), the only GM crop that is currently cultivated is Monsanto's maize event MON810, which is resistant to the European and Mediterranean corn borer. Throughout 2006 and 2007, the area planted with GM maize almost doubled, reaching the 100 thousand hectare milestone, spread over six countries (Table 1) [1]. Despite this enthusiasm, GM maize plantings still cover less than $2 \%$ of the total EU maize cultivation area. With this evolution, the question now arises of whether GM crops can 'coexist' with conventional and organic farming while still preserving freedom of choice for consumers [2]. Anticipating increasing adoption levels of GM crops in the European landscape, EU policy-makers are currently struggling to implement coherent coexistence regulations in all member states. Regulation 1829/2003 on GM food and feed, which entered into force in April 2004, provides the legal basis for coexistence in the EU [3]. According to Article 43 of the GM food and feed Regulation, member states are empowered to take appropriate measures to

Corresponding author: Demont, M. (m.demont@cgiar.org). avoid the unintentional presence of GM material in other products. Hence, farmers should maintain their ability to make a practical choice among conventional, organic and GM crops without excluding any agricultural options [4]. The maintenance of different agricultural production systems goes hand in hand with the ability of the food industry to deliver a high degree of consumer choice. However, guaranteeing the coexistence of different cropping systems might be difficult in the agricultural context if no specific measures are taken. In agriculture, various sources can lead to the unintentional presence of GM material in nonGM products. Such sources include the following: the use of impure seed; cross-fertilization due to pollen flow between neighboring fields; the occurrence of volunteer plants originating from seeds and/or vegetative plant parts from previous GM crops; mixing in machinery during sowing, harvest and/or post-harvest operations; and, to a lesser extent, cross-fertilization from certain sexually compatible wild relatives and feral plants [5-10].

Acknowledging the difficulty of keeping transgenes 'on a leash' [11], tolerance thresholds have been established for the unintentional or technically unavoidable presence of authorized GM material in non-GM products. In the EU, a tolerance threshold of $0.9 \%$ for food and feed has been agreed upon [3], although no threshold is officially in place for seeds to date [12]. At a meeting of the EU agriculture ministers, held in June 2007, it was decided that the $0.9 \%$ threshold would also apply for organic products, meaning that an organic product with an adventitious content of GM material below $0.9 \%$ could still be labeled as organic. It is often argued that there is no scientific justification for tolerance thresholds. Given that GM agro-food products are declared safe before marketing, tolerance thresholds are not related to safety or health issues. Instead, they reflect a political balance between differently framed requests and technical capabilities (the lower the threshold, the larger the error); agro-food and seed biotechnology companies request high thresholds, whereas non-governmental organizations and consumers demand lower ones. When the defined tolerance threshold is exceeded in the EU, the co-mingled product has to be labeled as containing a genetically modified organism (GMO). A lower market price or difficulties in selling products that contain traces of GM material could induce a loss of income. This economic damage is expected to be 
Table 1. Recent adoption of GM maize in the EU

\begin{tabular}{lll}
\hline Member state & Adoption & \\
\cline { 2 - 3 } & $\mathbf{2 0 0 6}$ & $\mathbf{2 0 0 7}$ \\
\hline Spain & 54000 ha $(15.3 \%)$ & 75000 ha $(20.5 \%)$ \\
France & 5000 ha $(0.3 \%)$ & 21000 ha $(1.4 \%)$ \\
Czech Republic & 1300 ha $(1.4 \%)$ & 5000 ha $(5.4 \%)$ \\
Portugal & 1250 ha $(1.2 \%)$ & 4500 ha $(3.9 \%)$ \\
Germany & 1000 ha $(0.2 \%)$ & 2700 ha $(0.7 \%)$ \\
Slovakia & 30 ha $(0.0 \%)$ & 900 ha $(0.6 \%)$ \\
Total EU & 62580 ha $(0.7 \%)$ & 109100 ha $(1.2 \%)$ \\
\hline
\end{tabular}

MON810 maize areas are based on calculations of Abbott and Schiermeier [1], and percentages between brackets represent GM maize shares in total grain maize plantings (Eurostat Agriculture and Fisheries Data 2008, http://epp.eurostat.ec. europa.eu) [51].

greater in organic farming than in conventional farming, owing to the generally higher market value of organic products. Furthermore, organic growers could lose their organic certification, precluding access to markets for organic products for several years. In the case of a conventional product, the GMO label might affect its market acceptability if consumers prefer GM-free products. Within the scope of coexistence, which extends from agricultural crop production on the farm up to the first point of sale (i.e. from the seed to the silo), agricultural commodities produced on-farm will have to comply with the labeling requirements at the first point of sale.

In this review, we show that the ongoing debate about the coexistence of GM and non-GM crops in the EU is characterized by an overemphasis on technical aspects and costs, which might lead EU policy-makers to regulate coexistence too stringently. Instead, we argue for a flexible approach that explicitly takes into account the economic incentives for coexistence. We provide a current perspective on coexistence and explore alternative approaches to regulate coexistence. Finally, we describe the implications for policy-makers.

\section{Current perspective on coexistence}

Regulations can be categorized into two groups: ex post regulations are backward-looking, whereas ex ante regulations are forward-looking. When driving a car, for example, most of us are aware of the ex ante regulatory speed limits, and some of us might have experienced the ex post liability consequences of not respecting these ex ante regulations. Regulating coexistence between different cropping systems is similar. Since the publication of the European Commission (EC) guidelines on coexistence [4], EU member states have established or are developing a diversity of ex ante regulations and ex post liability schemes for ensuring the practical coexistence between GM and non-GM crops [13]. In ex ante coexistence regulations, preventive on-farm measures are prescribed so that agricultural commodities comply with the established tolerance thresholds, whereas ex post liability schemes cover questions of liability and the duty to redress the incurred economic harm caused by adventitious mixing. Ten EU member states have now adopted such ex ante and ex post regulations [14].

In scientific and regulatory communities, the debate about coexistence has been centered mainly on the following aspects: preventive coexistence measures needed to keep the adventitious presence of GM material in non-GM products below established tolerance thresholds [5, 7-10,15-18]; the feasibility and costs of implementing such measures [16,19-23]; segregation costs and potential economic losses resulting from adventitiously co-mingled products [24-26]; who should bear the costs of coexistence measures [2,14]; and who should redress the incurred economic losses due to adventitious mixing [13]. Although these aspects are of fundamental importance when discussing coexistence strategies, they do not take into account the economic incentives for coexistence. Economic incentives for coexistence include either the adoption of GM technologies as a way to capture 'GM gains' or the cultivation of conventional GM-free crops as a way to capture 'GM-free gains' (Box 1). Until now, very few studies have acknowledged that the issue of coexistence is only relevant if there are sustainable economic incentives for supplying both GM and non-GM crops and for encouraging conventional and biotechnological agriculture to exist 'peacefully' next to each other in the long-run.

Coexistence is an issue only if both economic incentives 'coexist' in farming communities; if one incentive is lacking, strictly speaking there is no coexistence problem. Some farmers might adopt GM crops - and thus be prepared to invest in coexistence measures - if the benefits of planting GM crops (i.e. the GM gains) exceed the costs of implemented measures. Other farmers might gain more from preserving the GM-free status of their production. In any system of identity preservation (e.g. in the seed or organic sector), farmers aiming at preserving a specific product quality are responsible for undertaking the respective measures. By contrast, EU farmers cultivating non-GM crops have no legal obligation to undertake coexistence measures; instead, these are currently the responsibility of the GM farmer. However, farmers cultivating non-GM crops might have incentives to apply coexistence measures if they hope to receive a sufficient price premium for GMfree crops. By applying coexistence measures, they will avoid adventitious mixing, in turn ensuring a GM-free production. Given that the potential gains due to the cultivation of GM crops are lost when a farmer switches from GM to GM-free crops, GM-free gains must compensate lost GM gains.

In the EU, owing to the limited adoption of GM crops (Table 1), no economically important coexistence issues have been reported to date - even in Spain, the largest adopter of GM maize. In Canada, by contrast, owing to stringent organic standards (i.e. zero tolerance for GM content), organic farmers claim that the presence of GM canola varieties, and the occurrence of cross-fertilizations, makes it impossible for them to have their organically produced canola certified as organic [19].

\section{Regulating spatial coexistence: rigid versus flexible regulations}

The challenge for farmers is to keep the adventitious presence of GM material in non-GM products below the established tolerance thresholds, which ultimately involves minimizing cross-fertilization between neighboring fields. At present, two ex ante coexistence regulations have been proposed for this purpose: isolation distances and pollen barriers (Box 2) [13]. Given that pollen concentrations 


\section{Box 1. Economic incentives for coexistence: GM gains} versus GM-free gains

The economic benefits of GM crops (i.e. 'GM gains') include the following: increases in productivity and efficacy; production cost reductions; and non-pecuniary benefits, such as increases in management flexibility $[36,40,48,49]$. If there is a substantial demand for non-GM crops, this will be reflected by a price difference between GM and non-GM crops. In other words, non-GM crops will yield a price premium on the market, relative to GM crops $[25,26]$. GM-free crops are non-GM crops that are intended to be free of GM material, although they might contain an adventitious GMO content up to $0.9 \%$ in the EU [3]. At GMO contents above the threshold, nonGM crops do not acquire the unlabeled 'GM-free' status and have to be labeled and commercialized as 'containing a GMO' at the same price level as GM crops (i.e. without yielding any price premium on the crop market). When the purity threshold is met, 'GM-free gains' represent the total additional income generated through capturing price premiums for GM-free crops. As a comparison, in the USA, labeling of GM products is not mandatory, but voluntary GM-free labeling can be applied up to a threshold of $5 \%$ of GMO content [50].

GM-free price premiums differ from organic price premiums; products can only be labeled 'certified organic' if all procedures occurring along the supply chain (from crop production to processing) have been verified to comply with established organic standards [19]. One of the standards is the GM-free status, for which similar thresholds are applied (e.g. $0.9 \%$ threshold in the EU [13], 5\% in the US (United States Department of Agriculture, 'The National Organic Program: Program Standards', http://www.ams.usda.gov/nop/NOP/standards.html) and $0 \%$ in Canada [19]). Hence, organic crops are GM-free but GM-free crops are not necessarily organic. However, US experience shows that, in practice, most GM-free products at the retail level are organic products [50].

rapidly decrease with increasing distance from the pollen source, spatially isolating fields of GM crops from non-GM ones is a robust strategy to reduce the extent of crossfertilization. Based on the scientific literature on pollen dispersal and cross-fertilization and on predictive vertical gene flow modeling at the landscape level, it is generally suggested that isolation distances ranging from 10 to $50 \mathrm{~m}$ would be sufficient to keep the adventitious presence of GM material from cross-fertilizations below the tolerance threshold of $0.9 \%$ in the harvest of neighboring non-GM maize fields. The necessary isolation distance within the determined range will be influenced by the seed purity of non-GM maize, field characteristics and distribution, (GM) maize share, crop type, differences in sowing and flowering times and by meteorological conditions $[5,9,10,16,18]$. In a similar manner, plants sown around the source or recipient field can function as a pollen barrier and effectively reduce the extent of out-crossing between neighboring fields. First, by separating the inner parts of neighboring fields, pollen barriers act as an isolation distance, in turn increasing the distance GM pollen has to travel for cross-fertilization. Second, a pollen barrier - if the GM and non-GM crops in question are the same species - introduces competing pollen and/or can serve as a physical barrier to the flow of air and, consequently, the flow of pollen [16,27-31]. Accordingly, a pollen barrier reduces the extent of cross-fertilization much more effectively than an isolation perimeter of bare ground of the same width [32,33].

A recent case-study focusing on the interaction between the incentives and the costs of coexistence suggests that the costs of complying with rigid regulations, such as
Box 2. Rigid versus flexible coexistence regulations: isolation distances versus pollen barriers

Isolation distances are rules governing the minimum distance between GM and non-GM crop fields of the same species. If a farmer's field is too close to a neighboring farmer's non-GM field of a particular crop, the field has to be planted with other crops or the same crop species but with non-GM varieties. Pollen barriers are coexistence measures that rely on field margins that are planted with non-GM crops of the same species and which will need to be labeled as GMO-containing. Pollen barriers serve as cross-fertilization zones between GM and non-GM varieties of the same crops and can be planted on donor or recipient fields; the specifics of the barriers can be negotiated between neighboring farmers. Imposing measures on GM crop farmers - considering that GM crop production is the 'newcomer' in European countries [4] - introduces rigidity in coexistence regulations, whereas leaving measures open for negotiation between farmers introduces flexibility. Hence, in our definition, pollen barriers are better-suited measures than isolation distances for building flexibility into coexistence regulations.

excessive isolation distance requirements, are not proportional to the economic incentives of coexistence (i.e. GM versus GM-free gains) (Box 1) [34]. First, if consumers are not willing to pay significant price premiums for GM-free crops, isolation distances generate substantial losses for GM crop producers, who are denied GM gains from growing GM crops while hardly capturing any compensatory GM-free gains. The net loss (i.e. GM gains minus GM-free gains) is in no way proportional to the weak incentives for supplying GM-free crops. By contrast, if consumers are willing to pay substantial price premiums for GM-free crops, farmers who are denied GM gains will attempt to compensate these losses by planting non-GM crops while avoiding any adventitious mixing from GM crops and aiming to capture GM-free gains. In doing so, they risk triggering a domino effect at the landscape level by forcing other farmers to follow their example, illustrated in Figure 1 (see also Box 3).

By contrast, flexible measures such as pollen barriers (Box 2) should be negotiable amongst GM and non-GM farmers, because both have economic incentives to ensure coexistence in the long run. Theoretically, pollen barriers can be planted and cultivated by the GM farmer or the nonGM neighboring farmer. In the GM farmer's case, the area planted with the non-GM pollen barrier does not benefit from any GM gains and, hence, the cost of the pollen barrier is equal - and therefore proportional - to the lost GM-gains. In the non-GM farmer's case, the area planted with the non-GM pollen barrier is harvested separately, sold as 'GM' and, hence, does not benefit from any GM-free gains. In this case, the cost of the pollen barrier is equal and therefore proportional - to the lost GM-free gains. This cost is borne by the non-GM farmer and can be reimbursed by the GM farmer through a compensatory payment. Consequently, by design these measures are proportional to the GM and GM-free gains (i.e. the economic incentives for coexistence; Box 1) and, hence, less counterproductive for European agriculture [34]. Furthermore, additional nonrandom actions, such as the voluntary clustering of fields among different farms, would further reduce the costs of flexible coexistence measures, despite the organizational costs involved in coordinating farmers' planting intentions. This was already recognized in the EC guidelines on 


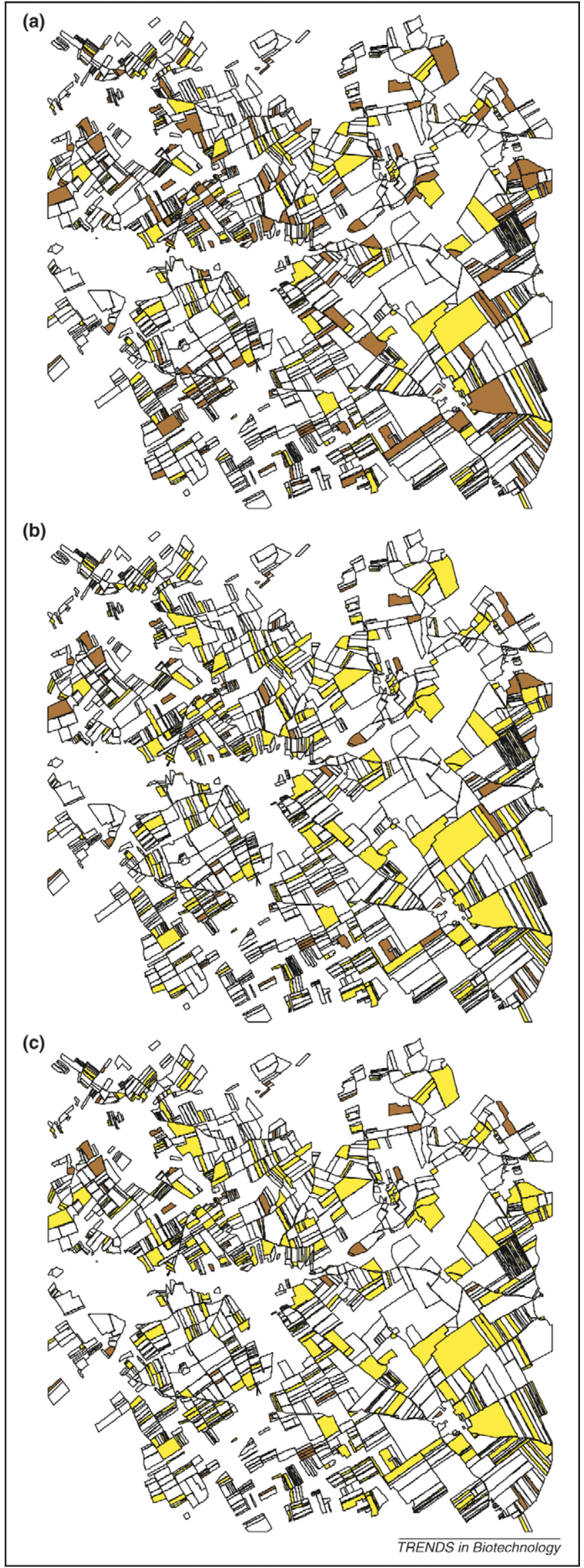

Figure 1. Illustration of the domino effect due to rigid coexistence regulations. The panels represent three different phases in the joint decision process of neighboring coexistence [4]. Therefore, as farmers are inclined to take decisions that minimize transaction costs, in the long run we expect clustering to precede any implementation of costly coexistence measures.

\section{Implications for EU policy-makers}

According to a recent Communication from the EC to the Council and the European Parliament, '[...]coexistence measures should not go beyond what is necessary to ensure that adventitious traces of GMOs stay below the labeling threshold[...]to avoid any unnecessary burden for the operators concerned. While some member states have taken this advice into account, others have decided to propose or adopt measures that aim to reduce adventitious presence of GMOs below this level. In some cases, proposed measures, such as isolation distances between GM and non-GM fields, appear to entail greater efforts for GM crop growers than necessary, which raises questions about the proportionality of certain measures.[...]While the [EC] recognizes the legitimate right to regulate the cultivation of GM crops to achieve coexistence, it stresses that any approach needs to be proportionate to the aim of achieving coexistence.' [13].

We argue that rigid coexistence regulations, such as large isolation distances, violate the proportionality condition and jeopardize the ability of some farmers to adopt GM crops and reduce their production costs. More alarmingly, the implementation of rigid rules could be misused by opponents of GM crops to create and extend GMO-free zones, even when the demand for GM-free crops is limited. We concur with Jank et al. [2] that GMO-free zones can be established as measures for coexistence, provided that they are proportional and temporal. Furthermore, the decision not to grow transgenic crops in a specific region should be taken in conjunction with the farmers and on a voluntary basis. However, we would like to emphasize that the existence of a sustainable demand for GM-free crops is a precondition to justify these extremely rigid and costly coexistence measures. This is important for policy-makers, because the debate about coexistence has been too often centered on technical aspects and costs instead of incentives. In September 2007, the European Court of Justice finally rejected general statutory regional bans of GMOs (e.g. in the case of Upper Austria), given that a statutory ban is a denial of the freedom of choice for farmers and consumers (http://www.europabio.org/articles/PR-Austrian_ECJ_070914.pdf).

We contend that flexible measures respect the proportionality condition and are also better adapted to the natural heterogeneity of GM gains and homogeneity of

farmers to grow GM or non-GM varieties of a crop in a hypothetical landscape. The crop in question, represented by the colored fields, is assumed to be part of a fouryear rotation cycle and is planted on a quarter of the total arable area. Half of this quarter is planted with a GM variety (brown fields) and the other half of the quarter is planted with a non-GM variety (yellow fields). (a) The depicted cropping pattern results from unconstrained, random planting decisions of farmers. (b) By complying with certain rigid isolation distances, some GM farmers need to convert their planting decisions to non-GM. This leads to a progressive reduction of GM crop plantings in the landscape. (c) The changed planting decisions create additional distance conflicts, thereby further removing GM crops from the landscape until all distance requirements are met and only small clusters of GM crop plantings remain. 


\section{Box 3. Domino effect}

The domino effect is the theoretical spillover effect of farmer decisions in a GM-free crops-favorable market. It is induced by enforcing rigid coexistence regulations on potential GM crop adopters. In the absence of any regulation, GM and GM-free planting options would coexist in a population of farmers. Through compliance with isolation distances, some potential GM crop adopters will have to modify their planting decisions (i.e. from GM to non-GM varieties) and will attempt to capture GM-free gains by complying with GM-free standards. These new GM-free farmers might, in turn, restrict planting options and convert planting decisions of neighboring GM farmers. Subsequently, this might affect other GM farmers' planting options and impinge on planting decisions, etc., until all distance requirements between GM and nonGM fields are met at the landscape level. The domino effect constrains potential adoption rates and raises the costs and the non-proportional character of rigid coexistence regulations. Its radius of action and intensity is essentially a function of the following factors: the degree of land fragmentation; the planting density and rotation cycle of the crop in the landscape; the legally enforced isolation distance; and the price premium consumers are willing to pay for GM-free crops. Contrary to common sense of intuition, the domino effect is not a direct function of the crop and the trait; it only depends on the biological properties of the crop and the trait insofar as these biological properties provide scientific evidence on crop-specific gene flow, which influences regulatory decisions on isolation distances [34].

GM-free gains. Because farmers operate under heterogeneous conditions with respect to land quality, pest pressure, managerial expertise, education and market access, the gains they capture from adopting GM crops might vary. GM-free price premiums, by contrast, apply to all farmers, because they are generated by the interaction of aggregate demand and supply (i.e. market share) on the market for non-GM crops. As long as consumers are willing to pay significant GM-free price premiums, highly productive areas, in which the incentive for growing GM crops is higher than the incentive for supplying GM-free crops, will cluster as GM regions, whereas low productive areas will rapidly form GMO-free zones $[19,35]$ in an attempt to capture the GM-free gains.

Profits from growing GM crops, although heterogeneous, have been more or less established after a decade of global GM crop adoption [36], whereas future GM-free price premium levels are still uncertain in the EU, owing to limited experience with the large-scale diffusion of GM crops (Table 1). Therefore, Europe's trade-off between planting GM crops and supplying GM-free crops will largely depend on the market signals stemming from consumer demand for GM-free products. This does not imply that, under weak market-signals for GM-free crops, the entire European landscape will be planted with GM crops. Experience has shown that GM crop adoption is usually incomplete, owing to several reasons. First, proprietary GM seed technologies are protected by intellectual property rights (i.e. patents) that confer monopoly rights to the discoverer - with some limitations. As a result, GM seed prices are higher than they would be in a perfectly competitive market, despite competition from chemical alternatives [37-39]. If biotechnology companies set the GM seed price at a uniform, monopolistic level among a heterogeneous group of farmers, some farmers would find it profitable to adopt the innovation, while others would not [39-41]. Other reasons for incomplete adoption include farmers' uncertainty about anticipated GM gains [42], and risk aversion towards new technologies, a well-known phenomenon in the literature on agricultural innovation $[43,44]$.

To date, price differentials for GM-free crops have been weak in international agricultural markets $[45,46]$. However, this might change if availability (i.e. market share) of GM-free products declines as a result of worldwide adoption of GM crops. Only if consumers have strong and sustainable preferences for non-GM crops, and only if they are willing to pay significant price premiums for them will some farmers have an incentive to supply GM-free crops. If the opposite holds, strictly speaking there is no coexistence issue and coexistence costs will purely reflect the costs of compliance to EU coexistence laws instead of the economic incentives for coexistence.

Authorities might be reluctant to adopt flexible ex ante regulations, but in the absence of clear market-signals for GM-free crops, regulatory rigidity should be shifted from $e x$ ante to ex post to avoid jeopardizing the economic incentives for coexistence and competitiveness of EU agriculture. Going back to our car example, our proposed model of regulation would be somewhat comparable to German traffic laws, wherein both enforced (rigid) and suggested (flexible) ex ante speed limits exist on highways. However, in case of a road accident, the driver can be held (ex post) liable for negligence if he did not comply with the ex ante speed limit during the accident [47]. Similarly, in their coexistence regulations, Germany is planning to introduce flexibility, which is currently highly debated among politicians and interest groups (http://www.agrizert.de/ uploads/media/Eckpunktepapier-Gentechnik.pdf).

\section{Conclusion}

Rigid coexistence regulations are not proportional to the economic incentives for coexistence, especially in the absence of strong market-signals for GM-free crops. Instead, we argue that flexible measures respect the proportionality condition, are less counterproductive for European agriculture and, hence, are more consistent with the objectives of the EC. Therefore, we recommend flexible $e x$ ante coexistence regulations, complemented by rigid and clearly defined ex post liability rules. Our arguments provide a timely framework for EU policy-makers, who currently face the challenge of implementing coherent coexistence regulations for the heterogeneous landscape of European agriculture.

\section{References}

1 Abbott, A. and Schiermeier, Q. (2007) Showdown for Europe. Nature 450, 928-929

2 Jank, B. et al. (2006) Co-existence of agricultural production systems. Trends Biotechnol. 24, 198-200

3 EC (2003) Regulation (EC) 1829/2003 of the European Parliament and of the Council of 22 September 2003 on genetically modified food and feed. Official Journal of the European Communities L268, 1-23 (http:// eur-lex.europa.eu/LexUriServ/site/en/oj/2003/1_268/

1_26820031018en00010023.pdf)

4 EC (2003) Commission Recommendation of 23 July 2003 on guidelines for the development of national strategies and best practices to ensure the coexistence of genetically modified crops with conventional and organic farming. Official Journal of the European Communities L189, 
36-47 (http://europa.eu.int/eur-lex/lex/LexUriServ/LexUriServ. do?uri=CELEX:32003H0556:EN:HTML)

5 Eastham, K. and Sweet, J. (2002) Genetically Modified Organisms (GMOs): The Significance of Gene Flow Through Pollen Transfer, European Environment Agency, Copenhagen, Denmark (http:// reports.eea.eu.int/environmental_issue_report_2002_28/en/ GMOs\%20for\%20www.pdf)

6 Demeke, T. et al. (2006) Adventitious presence of GMOs: Scientific overview for Canadian grains. Can. J. Plant Sci. 86, 1-23

7 Van De Wiel, C.C.M. and Lotz, L.A.P. (2006) Outcrossing and coexistence of genetically modified with (genetically) unmodified crops: a case study of the situation in the Netherlands. NJASWagen. J. Life Sc. 54, 17-35

8 Devos, Y. et al. (2004) Management of herbicide-tolerant oilseed rape in Europe: a case study on minimizing vertical gene flow. Environ. Biosafety Res. 3, 135-148

9 Devos, Y. et al. (2005) The co-existence between transgenic and nontransgenic maize in the European Union: a focus on pollen flow and cross-fertilization. Environ. Biosafety Res. 4, 71-87

10 Sanvido, O. et al. (2008) Definition and feasibility of isolation distances for transgenic maize cultivation. Transgenic Res. 17, 317-335

11 Marvier, M. and Van Acker, R.C. (2005) Can crop transgenes be kept on a leash? Front. Ecol. Environ. 3, 99-106

12 Devos, Y. et al. (2006) The interplay between societal concerns and the regulatory frame on GM crops in the European Union. Environ. Biosafety Res. 5, 127-149

13 EC (2006) Report on the Implementation of National Measures on the Coexistence of Genetically Modified Crops with Conventional and Organic Farming, Commission of the European Communities (http://ec.europa.eu/agriculture/coexistence/index_en.htm)

14 Beckmann, V. et al. (2006) Coexistence rules and regulations in the European Union. Am. J. Agric. Econ. 88, 1193-1199

15 Damgaard, C. and Kjellsson, G. (2005) Gene flow of oilseed rape (Brassica napus) according to isolation distance and buffer zone. Agric. Ecosyst. Environ. 108, 291-301

16 Messean, A. et al. (2006) New Case Studies on the Coexistence of GM and Non-GM crops in European Agriculture, European Commission Joint Research Centre (http://ftp.jrc.es/eur22102en.pdf)

17 Hüsken, A. and Dietz-Pfeilstetter, A. (2007) Pollen-mediated intraspecific gene flow from herbicide resistant oilseed rape (Brassica napus L.). Transgenic Res. 16, 557-569

18 Hoyle, M. and Cresswell, J.E. (2007) The effect of wind direction on crosspolination in wind-pollinated GM crops. Ecol. Appl. 17, 1234-1243

19 Furtan, W.H. et al. (2007) Landscape clubs: co-existence of genetically modified and organic crops. Can. J. Agr. Econ. 55, 185-195

20 Perry, J.N. (2002) Sensitive dependencies and separation distances for genetically modified herbicide-tolerant crops. Proc. R. Soc. Lond. B. Biol. Sci. 269, 1173-1176

21 Belcher, K. et al. (2005) Genetically modified crops and agricultural landscapes: spatial patterns of contamination. Ecol. Econ. 53, 387401

22 Devos, Y. et al. (2007) Implementing isolation perimeters around genetically modified maize fields. Agron. Sust. Dev. 27, 155-165

23 Devos, Y. et al. (2008) Feasibility of isolation perimeters for genetically modified maize. Agron. Sust. Dev. 28, 195-206

24 Moschini, G. et al. (2005) On the segregation of genetically modified, conventional, and organic products in European agriculture: a multimarket equilibrium analysis. J. Agr. Econ. 56, 347-372

25 Kalaitzandonakes, N.G. et al. (2001) Global identity preservation costs in agricultural supply chains. Can. J. Agr. Econ. 49, 605-615

26 Bullock, D.S. and Desquilbet, M. (2002) The economics of non-GMO segregation and identity preservation. Food Policy 27, 81-99

27 Weekes, R. et al. (2007) A study of crop-to-crop gene flow using farm scale sites of fodder maize (Zea mays L.) in the UK. Transgenic Res. 16, 203-211

28 Gustafson, D.I. et al. (2006) Empirical modeling of genetically modified maize grain production practices to achieve European Union labeling thresholds. Crop Sci. 46, 2133-2140
29 Messeguer, J. et al. (2006) Pollen-mediated gene flow in maize in real situations of coexistence. Plant Biotechnol. J. 4, 633-645

$30 \mathrm{Pla}$, M. et al. (2006) Assessment of real-time PCR based methods for quantification of pollen-mediated gene flow from GM to conventional maize in a field study. Transgenic Res. 15, 219-228

31 Weber, W.E. et al. (2007) Coexistence between GM and non-GM maize crops - tested in 2004 at the field scale level (Erprobungsanbau 2004). J. Agron. Crop Sci. 193, 79-92

32 Staniland, B.K. et al. (2000) Effectiveness of border areas in confining the spread of transgenic Brassica napus pollen. Can. J. Plant Sci. 80, $521-526$

33 Della Porta, G. et al. (2008) Maize pollen mediated gene flow in the Po valley (Italy): Source-recipient distance and effect of flowering time. Eur. J. Agron. 28, 255-265

34 Demont, M. et al. (2008) Regulating coexistence in Europe: beware of the domino-effect! Ecol. Econ. 64, 683-689

35 Beckmann, V. and Wesseler, J. (2007) Spatial dimension of externalities and the Coase theorem: Implications for co-existence of transgenic crops. In Regional Externalities (Heijman, W., ed.), pp. 223242 , Springer

36 Demont, M. et al. (2007) GM crops in Europe: how much value and for whom? EuroChoices 6, 46-53

37 Lapan, H.E. and Moschini, G. (2000) Incomplete adoption of a superior innovation. Economica 67, 525-542 (http://www.econ.iastate.edu/ faculty/moschini/adopt-Sept-99-StaffPaper.pdf)

38 Alexander, C. et al. (2002) Determinants of GMO use: a survey of Iowa corn-soybean farmers' acreage allocation. In Market Development for Genetically Modified Foods (Santaniello, V. et al., eds), pp. 127-139, $\mathrm{CAB}$ International

39 Weaver, R.D. (2004) R\&D incentives for GM seeds: restricted monopoly, non-market effects, and regulation. In The Regulation of Agricultural Biotechnology (Evenson, R.E. and Santaniello, V., eds), pp. 143-151, CAB International

40 Demont, M. et al. (2008) Ex ante impact assessment under imperfect information: biotechnology in new member states of the EU. J. Agr. Econ. DOI: $10.1111 /$ j.1477-9552.2008.00157.x

41 Oehmke, J.F. and Wolf, C.A. (2004) Why is Monsanto leaving money on the table? Monopoly pricing and technology valuation distributions with heterogeneous adopters. J. Agr. Appl. Econ. 36, 705-718

42 Weaver, R.D. and Wesseler, J. (2004) Monopolistic pricing power for transgenic crops when technology adopters face irreversible benefits and costs. Appl. Econ. Lett. 11, 969-973

43 Feder, G. et al. (1985) Adoption of agricultural innovations in developing countries: a survey. Econ. Dev. Cult. Change 33, 255-298

44 Sunding, D.L. and Zilberman, D. (2001) The agricultural innovation process: research and technology adoption in a changing agricultural sector. In Handbook of Agricultural Economics (Vol. 1) (Gardner, B.L. and Rausser, G.C., eds,) pp. 207-261, Elsevier

45 Foster, M. and French, S. (2007) Market Acceptance of GM Canola, Australian Bureau of Agricultural and Resource Economics, Canberra (http://www.abareconomics.com/publications_html/crops/crops_07/ GM_canola.pdf)

46 Falck-Zepeda, J.B. (2006) Coexistence, genetically modified biotechnologies and biosafety: implications for developing countries. Am. J. Agric. Econ. 88, 1200-1208

47 Müller, D. (2007) Geschwindigkeit als Unfallursache. Zeitschrift für die Praxis des Verkehrsjuristen 1, 1-6

48 Demont, M. et al. (2004) Biodiversity versus transgenic sugar beet: the one Euro question. Eur. Rev. Agric. Econ. 31, 1-18

49 Demont, M. and Tollens, E. (2004) First impact of biotechnology in the EU: Bt maize adoption in Spain. Ann. Appl. Biol. 145, 197-207

50 Gruère, G.P. (2006) A preliminary comparison of the retail level effects of genetically modified food labelling policies in Canada and France. Food Policy 31, 148-161

51 Ollier, C. and Utz, H. (2007) Main Crop Areas in the European Union in 2007, European Communities, Luxembourg (http:// epp.eurostat.ec.europa.eu/cache/ITY_OFFPUB/KS-SF-07-086/EN/KSSF-07-086-EN.PDF) 